\title{
In Silico Analysis of the Effects of Amino Acid Substitution in Kiss 1 Receptor \\ Musa Suleiman Ibrahim*
}

Department of Animal Science, Nasarawa State University, Keffi, Nigeria

DOI: $10.36348 /$ sjbr.2020.v05i08.001 | Received: 07.08.2020 | Accepted: 14.08.2020 | Published: 16.08 .2020

*Corresponding author: Musa Suleiman Ibrahim

\section{Abstract}

The regulatory role of kisspeptin and its receptor, G protein coupled receptor 54 (GPR54) on reproductive processes is well documented. The main objective of this study is to determine the effects of non synonymous single nucleotide polymorphism in kiss 1 receptor gene of sheep (F $195 \mathrm{~L})$. The amino acid sequence (>HM135393) was retrieved from the data bank of National Centre for Biotechnology Information (NCBI, db SNP). Analysis using panther indicated the damaging effects of substitution of Phenylalanine with Leucine at position 195 of the amino acid sequence of Kisspeptin. Effects of single nucleotide polymorphism was also predicted to be deleterious by Provean software. The study provide useful information on the potential role of Kiss 1 receptor gene in regulating reproductive traits in sheep. Findings of this research highlights the role of GPR54 as an efficient genetic marker for improving reproductive performance of farm animals.

Keywords: In silico, Kisspeptin, Polymorphism, Sheep.

Copyright @ 2020: This is an open-access article distributed under the terms of the Creative Commons Attribution license which permits unrestricted use, distribution, and reproduction in any medium for non-commercial use (NonCommercial, or CC-BY-NC) provided the original author and source are credited.

\section{INTRODUCTION}

Kisspeptin 1 receptor also known as $\mathrm{G}$ protein coupled receptor 54 (GPR54) is the endogenous receptor of Kisspeptins which are peptides products of Kiss 1 gene [1]. Kiss 1 receptor is an important regulator of the onset of puberty and reproductive functions in many species. $G$ protein coupled receptor (Kiss 1 receptor) are mediators of physiological responses to hormones, neurotransmitters and environmental stimulants [2]. Kisspeptins are essential mode of communication between external and internal cellular environments. The peptide is reported to play a significant role in the regulation of reproductive processes [3].

Single nucleotide polymorphism in Kiss 1 receptor gene significantly affect litter size and birth weight. Polymorphism of GPR54 are also associated with reproductive efficiency in sows and could be used as a potential genetic marker for improving reproductive functions [4]. Kisspeptins are reported to stimulate the release of gonadotrophins from the pituitary gland by activating the release of Gonadotrophin releasing hormone. The activation of $\mathrm{G}$ protein coupled receptor 54 which is richly expressed by GnRH neurons result in the release of GnRH. Findings indicate that $\mathrm{G}$ protein coupled receptor 54 /
Kisspeptin play a significant role in the regulation of GnRH secretion [1].

\section{MATERIALS AND METHODS}

Amino acid sequence of $\mathrm{G}$ protein coupled receptor 54 (aries ovis) with accession number >HM135393 was retrieved from the data bank of National Centre for Biotechnology Information ( $\mathrm{db}$ SNP) for analysis.

Analysis of the effect of single nucleotide polymorphism using panther

Protein analysis through evolutionary relationship is a resource for gene analysis based on evolutionary history and functions [5]. The server uses gene ontology tool for functional classification. Panther estimates the likelihood that a non-synonymous SNP will cause a functional impact on the protein as described by [6].

Use of Protein Variation Analysis server for predicting effect of single nucleotide polymorphism clustering of BLAST hits is performed by CD-HIT with a parameter of $75 \%$ global sequence identity. The top 30 clusters of closely related sequences form the supporting sequence set, which will be used to generate the prediction. A delta alignment score is computed for each supporting sequence. The scores are then averaged 
within and across clusters to generate the final PROVEAN score. If the PROVEAN score is equal to or below a predefined threshold (e.g. -2.5), the protein variant is predicted to have a "deleterious" effect. If the PROVEAN score is above the threshold, the variant is predicted to have a "neutral" effect [7].

\section{RESULTS AND DISCUSSION}

PSEP (position-specific evolutionary preservation) measures the length of time (in millions of years) a position in current protein has been preserved by tracing back to its reconstructed direct ancestors. The longer a position has been preserved, the more likely that it will have a deleterious effect. The thresholds we chose were: "probably damaging" (time > $450 \mathrm{my}$, corresponding to a false positive rate of $\sim 0.2$ as tested on HumVar), "possibly damaging" (450my > time $>200 \mathrm{my}$, corresponding to a false positive rate of 0.4) and "probably benign" (time < 200my).

\section{Panther HMM: G-Protein Coupled Receptor (PTHR24230)

\begin{tabular}{|l|l|l|}
\hline Substitution & Preservation Time & Message \\
\hline F195L & 456 & Probably Damaging \\
\hline
\end{tabular}

Fig-1: Predicting the effect of single nucleotide polymorphism using Panther server

\begin{tabular}{|c|c|c|}
\hline \multicolumn{3}{|c|}{ Query sequence (fasta) } \\
\hline \multicolumn{3}{|c|}{ Supporting sequence set used for prediction } \\
\hline \multicolumn{3}{|c|}{ Number of sequences: 91 (fasta, E-values) } \\
\hline \multicolumn{3}{|c|}{ Number of clusters: $\mathbf{3 0}$} \\
\hline \multicolumn{3}{|c|}{ Score thresholds for prediction } \\
\hline \multicolumn{3}{|c|}{ (1) Default threshold is -2.5 , that is: } \\
\hline \multirow{2}{*}{\multicolumn{3}{|c|}{$\begin{array}{l}\text {-Variants with a score equal to or below }-2.5 \text { are considered "deleterious," } \\
\text {-Variants with a score above }-2.5 \text { are considered "neutral." } \\
\text { (2) How to use a more stringent threshold. }\end{array}$}} \\
\hline & & \\
\hline Variant & PROVEAN score & Prediction $($ cutoff $=-2.5)$ \\
\hline F195L & -4.872 & Deleterious \\
\hline
\end{tabular}

Fig-2: Analysis of the effects of single nucleotide polymorphism using PROVEAN Server

Analysis using panther indicated the damaging effects of substitution of Phenylalanine with Leucine at position 195 of the amino acid sequence of Kisspeptin. Effects of single nucleotide polymorphism was also predicted to be deleterious by Provean software. The regulatory role of kisspeptin and its receptor, GPR54 on reproductive processes have been reported [8]. Kisspeptins are reported to activate the release of gonadotrophins by stimulating the secretion of $\mathrm{GnRH}$. The activation of GPR54 which is richly expressed by GnRH neurons lead to yhe release of GnRH. The regulatory role of kisspeptis/GPR54 on the GnRH secretion has been documented [1]. Kisspeptins bind to GPR54 in the GnRH neurons in the hypothalamus leading to the release of GnRH which in turn stimulate the release of follicle stimulating hormone and luteinizing hormone from the pituitary gland [9]. The absence of functional kisspeptin resulted in failure to attain puberty and exhibition of hypogonadotropic hypogonadism. The critical role of kisspeptins / GPR54 in the initiation of puberty has been reported [10]. The hypothalamic expression of GPR54 varies through the estrous cycle lower expression in anestrous sows [11]. Single nucleotide polymorphism in kiss1 gene has been associated with prolificacy in sheep [12]. SNP in kisspeptin also resulted in significant increase in lither size of goats indicating the important role of kisspeptin in determining fecundity traits [13]. The study provide useful information on the potential role of kiss 1 receptor gene in regulating reproductive traits in sheep. Findings of this study indicate that polymorphism in
GPR54 could be a useful genetic marker for improving reproductive efficiency in farm animals.

\section{REFERENCES}

1. Dungan, H. M., Clifton, D. K., \& Steigner, R. A. (2006). Minireview; Kisspeptin Neurons as central processors in the regulation of gonadotropin releasing hormone Secretion. Endocrinology. 147(3):1154-1158.

2. Daniel, M. R., Seren, G. F., \& Brian, K. K. (2009). The structure and function of $\mathrm{G}$ protein coupled receptors. Nature. 459(7245): 356-363.

3. Sadredin, A. M., \& Saber, Q. (2019). Polymorphism identification in ovine Kiss 1 receptor/ GPR54 gene among pure and cross breeds of Iranian sheep. Small Ruminant Research. 173; 23-29

4. Fen, W., Wei, Z., Qian-Qian, S., Hai, H., Ming, S., Gua, L., \& Jin, Z. (2019). Association analysis of polymorphism of $\mathrm{G}$ protein coupled receptor 54 gene Exons with reproductive traits in Jiaxing Black Sows. Asian Australian Journal of Animal Science. 32(8):1104-1111.

5. Huaiya, M., Anushiya, M., Dustin, E., Xiaosong, H., \& Paul, D. J. (2019). Panther version 14: More genome, a new panther go - slum and improvements in enrichment analysis Tools. Nucleic Acid Research. 47: 419-426.

6. Tang, H., \& Thomas, P. D. (2016). Panther- PSEP: Predicting disease causing genetic variants Using 
positive -specific evolutionary preservation. Bioinformatics. 32(14):2230-22.

7. Choi, Y., Sims, G. E., Murphy S., Miller, J. R., \& Chan, A. P. (2012). Predicting the Functional Effect of Amino Acid Substitutions and Indels. PLoS ONE. 7(10): e46688.

8. Zheng, J., Sayed, H. A., Xiang, D. Z., \& Jiang, H. L. (2018). Comparing kiss 1 and GPR54 Genes between two breeds of goats with low and high prolificacy. Genetics And Molecular Research. 17(4):1-11.

9. Babeker, A., \& Al-sheik, A. (2016). The role of kisspeptin signalling in control of reproduction in genetically similar species. Sudan Journal of Paediatrics. 16(1): 9-16.

10. Luan, X., Zhou, Y., \& Wang, W. (2007). Association study of the polymorphism In kiss 1 gene with central precocious puberty in chinese girls. European Journal of Endocrinology. 157(1):113-118

11. El Tarabeny, M. S., Zaglool, A. W., El-Tarabeny, A. A., \& Awad, A. (2017). Association analysis of polymorphisism in Kiss 1 gene with Reproductive traits in goats. Animal Reproduction Science. 180:92-99.

12. Mingxing, C., Chaoting, R., \& Ning, L. (2012). Polymorphism of Kiss 1 and GPR54 genes and their relationship with litter size in sheep. Molecular Biology Reports. 39: 3291 -3297.

13. Getinet, M., Joram, M., Todelle, D., Okeya, M., \& Solomon, A. (2018). Polymorphism Anakysis of kisspeptin gene and its association with lither size in European indigenous goats population. African Journal of Biotechnology. 16 (22):1254 -1264. 